\section{Effects of the Management Control System on Empowerment and Organizational Resilience}

\author{
Ilse Maria Beuren ${ }^{1}$ \\ ilse.beuren@gmail.com | (D) 0000-0003-4007-6408 \\ Vanderlei dos Santos ${ }^{1}$ \\ vanderleidossantos09@gmail.com | (D)0000-0002-9841-3780 \\ Daniele Cristina Bernd ${ }^{1}$ \\ dcbernd@hotmail.com | (D)0000-0002-9195-9510
}

\begin{abstract}
The aim of this study is to examine the effects of the enabling perception of the Managerial Control System (MCS) on psychological empowerment and organizational resilience. A survey was conducted with 161 managers of Brazilian companies that had undergone the process of acquiring another company and a structural model was developed to answer the hypotheses of the research. The results show that the enabling perception of MCS is associated with psychological empowerment and capacity for organizational resilience, which indicates that the characteristics of the MCS affect managers' motivation regarding their work environment and contribute to companies dealing effectively with adversities and contingencies. MCSs help organizations in the process of absorbing changes and regaining balance after some temporary disruption, as in the case of acquiring other companies. It is concluded that enabling MCSs favors the empowerment of managers and supports companies in dealing more effectively with the turbulence to which they are exposed.
\end{abstract}

\section{KEYWORDS}

enabling managerial control system; psychological empowerment; organizational resilience.
${ }^{1}$ Universidade Federal de Santa Catarina, Florianópolis, SC, Brasil

Received: 09/04/2018

Revised: 02/18/2019.

Accepted: 07/29/2019.

Published Online: 02/10/2020.

DOI: http://dx.doi.org/10.15728/bbr.2020.17.2.5 


\section{INTRODUCTION}

The design and use of Management Control Systems (MCS) affects the behavior of individuals within an organization (Hall, 2008). Enabling systems are perceived as facilitating their responsibilities (Adler \& Borys, 1996; Burney, Radtke \& Widener, 2017), as opposed to control devices for top management use (Free, 2007; Chapman \& Kihn, 2009). The enabling formalization exerts power over individual behaviors (Hempel, Zhang \& Han, 2012), making employees feel facilitated or motivated by the existing rules and systems (Wouters \& Wilderom, 2008).

Enabling MCSs provide greater interaction between the system and its users by providing mechanisms that support and stimulate the resolution of problems (Adler \& Borys, 1996), provide feedback, and reveal opportunities for improvement (Wouters \& Wilderom, 2008). These mechanisms motivate the interactions of managers at different hierarchical levels (Hartmann \& Maas, 2011), and can improve organizational members' understanding of their individual operational tasks regarding the organizational objectives (Ahrens \& Chapman, 2004).

Amongst the possible behaviors of individuals who would be affected by the enabling perception of the MCS, this study focuses on psychological empowerment (in the scope of individual analysis) and organizational resilience (in the scope of organizational analysis). Psychological empowerment, as understood as the intrinsic motivation of an individual in his work environment, manifests itself under four cognitions: meaning, competence, self-determination, and impact (Spreitzer, 1995). Although it is recognized that psychological empowerment affects behaviors that improve managerial performance (Hall, 2008), research such as that carried out by Hall (2008), Mahama and Cheng (2013), Moulang (2015), Appuhami (2017), Souza, Anzilago and Beuren (2017) does not allow conclusive inferences to be drawn about the effects of the MCS on dimensions of psychological empowerment.

Organizational resilience is presumed to also be affected by the enabling perception of the MCSs, understood as the organization's ability to prepare, respond, and recover from unexpected events (Annarelli \& Nonino, 2016) in times of crisis and in complicated, uncertain, and threatening environments (Akgün \& Keskin, 2014), while seeking to maintain desirable functions and outcomes amid tension (Linnenluecke, 2017). Few studies have focused on exploring managerial antecedents related to this construct, such as the ones carried out by Ignatiadis and Nandhakumar (2007) and Limnios, Mazzarol Ghadouani and Schilizzi (2014), although they have approached this matter when discussing characteristics of information systems. Limnios et al. (2014) point out that the magnitude of resilience will depend mainly on the characteristics of the organizational system and its ability to interact with the environment in an offensive (adaptive) or defensive (reactive) manner and persist. Thus, it is assumed that the MCS with more flexible characteristics favors changes and helps individuals to face challenges, giving them greater capacity for organizational resilience.

The interaction between psychological empowerment and organizational resilience also deserves to be explored, since empowerment, through positive cognition, influences organizational behavior, either through bringing about coping or motivation when facing adverse events (Spreitzer \& Doneson, 2005). Brodsky and Cattaneo (2013) point out the need for further studies on limits and interactions between these variables, and to better understand their differences, actions, and results at the individual, community and social levels. Research can help clarify how more autonomous individuals can react and assist with organizational outcomes. 
Given the above, the objective of this research is to examine the effects of the enabling perception of MCS on empowerment and organizational resilience. Complementarily, the interaction between psychological empowerment and organizational resilience is analyzed. The theoretical lens of the study is the Self-Determination Theory (SDT), by Deci and Ryan (1985), on the assumption that one of the principles of the MCSs is to motivate employees to achieve organizational purposes (Liu \& Leitch, 2013). SDT can help to understand how social forces and managerial behaviors affect individuals at work and how this reflects on organizational behavior. This is consistent with the evidence that environments that support autonomy lead to higher autonomous motivation and favor more adaptive cognitive, affective, and behavioral outcomes (Vallerand, Pelletier \& Koestner, 2008).

According to Lengnick-Hall and Beck (2005), the combination of skills with cognitive, behavioral, and contextual routines in the scope of an organization contributes to the development of organizational resilience. Similarly, the combination of individual attributes, systematically developed and integrated through the company's human resources management system, also contributes to organizational resilience (Lengnick-Hall, Beck \& Lengnick-Hall, 2011). Thus, this study assumes that the combination of managerial practices at the organizational level (MCS), in parsimony with influence at the individual level (empowerment), act together to support organizational resilience.

This study contributes to the literature by jointly analyzing these interactions, which were previously explored in isolation or in a single scope of analysis (organizational or individual). It also provides insight into how enabling MCSs are implicated and contribute to explaining managerial phenomena through the lens of the Self-Determination Theory by providing evidence on how they can influence individual and organizational behaviors. Moreover, it supports the need for attention to the psychological processes through which behavior can be influenced (Hall, 2008).

This study also contributes empirically by considering that social context influences the motivational scope of individuals and the behaviors which will derive from their perceptions. When individuals realize that their organizations enable them, and this action is able to promote greater autonomy, competence, and a better relationship with the organization (Ryan \& Deci, 2000), they will feel motivated and empowered and, as a result, will tend to act more positively when facing organizational adversity and change. The results of the study suggest that organizational resilience is achieved by a set of forces enacted by individuals that make up the workplace and formal systems, who are able to adapt to social environments that have routines changed in times of adversity and crisis.

\section{THEORETICAL DEVELOPMENT AND RESEARCH HYPOTHESES}

The Self-Determination Theory (SDT), by Deci and Ryan (1985), states that individuals have three innate psychological needs: (i) autonomy, or being able to make or contribute, by their own actions, to their choices; (ii) competence, feeling able to perform activities successfully; and (iii) relationships, feeling that they belong and are valued by the group (Ryan \& Deci, 2000). This theory predicts that autonomous motivation (internalized motivation processes) can affect employee behavior in the organizational environment (Ryan \& Deci, 2000). Thus, when the organization supports the autonomy of its employees, it fosters autonomous motivation (Gagne $\&$ Deci, 2005). 
BBR

17

214

One way to reinforce the three innate psychological needs of individuals within organizations is through the design and use of MCSs. Van der Hauwaert and Bruggeman (2015) suggest that the enabling MCSs assist in the creation of an organizational environment capable of enhancing motivation, competence and relationships. The proposition of enabling systems triggered by Adler and Borys (1996) predicts that the enabling formalization consists of procedures that help employees deal with contingencies in their workplace so that they can complete their tasks, and provides organizational memory to captures lessons learned from the experience. Therefore, it emphasizes the resources required in formal control systems to promote flexibility (Ahrens \& Chapman 2004).

The enabling formalization of the systems comprises four main characteristics: (i) repair, which is the ability of users to handle unanticipated breakdowns without allowing these unexpected events to disrupt the processes of work; (ii) internal transparency, or the ability to understand the logic and the processes of the system, with the information available; (iii) global transparency, which provides employees with insight into how systems and local elements fit together, as well as an understanding of how their tasks fit into the organization as a whole; and (iv) flexibility, which addresses the possibility of modifying or adapting the system as necessary (Adler \& Borys, 1996; Ahrens \& Chapman, 2004; Wouters \& Roijmans, 2011).

The enabling MCSs provide detailed and objective information, clarify responsibilities, and encourage experimentation (Wouters \& Wilderom, 2008). By stimulating control and autonomy, they are able to generate feelings of satisfaction and motivation (Adler \& Borys, 1996). When designed and used in an enabling manner, managers' attitudes tend to be more positive, as they feel facilitated or motivated by the existing rules and systems (Wouters \& Wilderom, 2008). The enabling formalization has the power to improve individual behavior and outcome variables (Hempel et al., 2012) as it enables them to perform their tasks better (Van der Hauwaert \& Bruggeman, 2015).

Thus, in line with SDT, which predicts that autonomy, competence, and relationships are an individual's three innate psychological needs (Hall, 2008), this study includes cognitive and motivational variables that may reveal connections with individual behaviors (psychological empowerment), which can help to understand how MCSs affect organizational behaviors at work (organizational resilience).

\subsection{ENABLING MANAGEMENT CONTROL SYSTEM AND PSYCHOLOGICAL EMPOWERMENT}

Psychological empowerment is a multidimensional concept that reflects a motivational psychological state related to the organizational environment (Thomas \& Velthouse, 1990; Spreitzer, 1995). It represents in itself a kind of autonomous motivation (Sun, Zhang, Qi \& Chen (2012) for supporting the autonomy of their employees (Gagne \& Deci, 2005). There are four cognitions or psychological states which are associated with empowerment: meaning (the value that an individual gives to a work purpose), competence (the individual's belief in their ability to successfully perform the necessary activities), self-determination (the sense of choice and autonomy in their work), and impact (the individual's belief in their ability to influence work outcomes) (Thomas \& Velthouse, 1990; Spreitzer, 1995; Moulang, 2015).

In order to empower the organization, it is necessary to facilitate and expand access to information about work operations and organizational performance for different levels and through different devices (Spreitzer, 1995). Sharing information creates a sense of meaning and purpose, and strengthens the sense of competence for the individual to believe that he is a valuable element 
in the organization (Spreitzer, 1995; 1996). Empirical studies indicate that empowerment of employees is positively related to attitudes at work, but little is known about what organizations do and which antecedent factors influence the psychological empowerment (Hempel et al., 2012).

Research in the accounting area (Hall, 2008; Mahama \& Cheng, 2013; Mouang, 2015; Appuhami, 2017; Souza et al., 2017; Souza \& Beuren, 2018) provide evidence that the design and use of MCS interfere with the empowerment of the individuals. Hempel et al. (2012) argue that organizational formalization can act to promote empowerment, as it can provide a useful direction for an organization, regardless of whether or not it is centralized; and that it plays a significant role in providing predictability, guidance and clarity, helping to avoid the chaos and unpredictability that can occur under conditions of high levels of organizational decentralization.

Thus, the enabling MCSs constitute one of the antecedents of psychological empowerment. The enabling MCSs can provide a sense of involvement by encouraging reduction in power disparities and expanding the sharing of knowledge, skills, and rewards across all organizational levels (Adler \& Borys, 1996). Expanding the limits of decision-making for the employees reflect in their empowerment, self-esteem, and determination within their organizational activities (Kantur \& Iseri-Say, 2012). Individuals will become more empowered when feeling involved and taking a more active role in the organization. This implies flexible authority and minimal formalization of tasks, while setting clear goals, tasks, and lines of responsibility (Spreitzer, 1996).

Enabling MCSs can increase the feeling of empowerment across all dimensions. They can provide employees with greater access to information and promote competence, as they are designed to increase individuals' knowledge of how their industry works (Chapman \& Kihn, 2009) and provide feedback on their performance (Adler \& Borrys, 1996). They can also increase self-determination by providing a range of information, such as organizational performance, goals, and performance measurements, which helps employees do their work independently (Hall, 2008; Mahama \& Cheng, 2013). They can favor greater integration of individuals with their company activities by encouraging them to contribute and influence the achievement of organizational goals, which implies increasing their sense of meaning (Ahrens \& Chapman, 2004). Impact consists of the individual's feeling of making a difference in the organization and can come from the principles of global transparency and flexibility, as the enabling perception of the MCSs provide a framework for discussing managers' decisions and actions (Hartmann \& Maas, 2011) and the ability to make changes and decisions when needed (Ahrens \& Chapman, 2004).

It is argued that the enabling MCSs can meet the autonomy, competence, and relationship needs of individuals mentioned in the SDT. According to Van der Hauwaert and Bruggeman (2015), competence can be reflected by characteristics of repair, internal transparency, and global transparency of the systems, as well as by promoting the perception that employees are capable, have mechanisms to cope with adverse situations, and how the systems and local elements fit into the organization as a whole. Autonomy can be driven by repair, internal transparency, and flexibility, by providing employees autonomy to control and change the system when necessary. Finally, relationships can be formed by characteristics of global transparency and flexibility by fostering a sense of belonging and kinship, in which individuals feel more connected to the organization and able to make changes when needed. Based on the aforementioned arguments, the first hypothesis is formulated:

H1: The enabling perception of the MCS positively influences psychological empowerment. 
BBR

17

216

Although there is evidence that the four dimensions are distinct, they together reflect a general construct of psychological empowerment (Spreitzer (1995), by combining themselves additively (Thomas \& Velthouse, 1990). In addition, a simple additive formulation seems to present better predictive validity than a more complex formulation involving the four dimensions (Spreitzer, 1996).

\subsection{ENABLING MANAGEMENT CONTROL SYSTEM AND ORGANIZATIONAL RESILIENCE}

In the face of a disturbing event, organizational strategies, goals, and achievements need to be effectively communicated throughout the organization (Barasa, Mbau \& Gilson, 2018). It is also necessary to proactively monitor what is happening in its environment. According to Barasa et al. (2018), organizations can identify warning signs that precede a crisis by monitoring the internal and external environments. This implies making a broad flow of information available to employees, which can help them interact creatively with the organization and the environment (Adler \& Borys, 1996).

The adaptive capacity in this context, which is capable of turning adversity into an opportunity, with people who can quickly respond to changes, provides a competitive edge. An organization's ability to leverage its resources and capabilities by exploring and creating opportunities highlights transformational power and organizational resilience (Lengnick-Hall et al., 2011). For this to happen, the company must make resources of various kinds available to its employees (Kantur \& Iseri-Say, 2012). Organizations must maintain a flexible and interactive posture in both their actions and involvement with their employees. The use of enabling controls capitalizes on managers' intelligence, giving them the freedom to innovate when facing contingencies, unexpected events, and obstacles that compromise organizational goals (Free, 2007). Depending on the degree of strictness in the information system rules, the company may become less able to flexibly and efficiently respond to changes and stressful conditions and, as a result, becomes less resilient (Ignatiadis \& Nandhakumar, 2007). According to these authors, softening these rules can lead to greater flexibility (at the cost of partial loss of control) and, thus, resilience may increase.

In this sense, it is possible to make an analogy with the enabling MCSs, as flexibility is a feature of these systems (Adler \& Borys, 1996) and a learning opportunity (Burney et al., 2017). Enabling control is associated with spontaneity, transparency of operations, rapid adaptation, sharing information, and adaptability (Mundy, 2010), which is essential to resilient organizations (Barasa et al., 2018). The enabling MCS is especially useful if the uncertainty originates outside the budget unit (Hartmann \& Maas, 2011), where the elements that characterize this type of system are most utilized for dealing with contingencies.

A required behavioral element of organizational resilience refers to the ability to take actions different from those formally envisaged by standards (Lengnick-Hall et al., 2011). For this, creative, flexible, and proactive strategic actions are raised, oriented to elastic solutions (Kantur $\&$ Iseri-Say, 2012). Thus, if an organization develops values that lead to investigative habits, collaborative routines, and traditions of flexibility, as is done by the enabling MCSs, it is more likely that it will behave intuitively in a way that opens (shares) the system and creates robust responses (Lengnick-Hall et al., 2011).

Fiksel (2003) points out that, sometimes, greater resilience is achieved through the simplicity of system's design, which reduces the chances of failure or unexpected interruption. According to Mundy (2010), the enabling MCSs are more complete (with data) and flexible, involve fewer rules, and are more informal. They are generally applied when employees are willing to independently deal directly with challenges in their work (Chapman \& Kihn, 2009), as they allow employees 
o make corrections and adaptations as needed (Ahrens \& Chapman, 2004). Beuren and Santos (2019) observed that the enabling characteristics of the MCS contribute to the interpretation of uncertain situations in a more creative way they favor the ability to conceive unconventional activities, take advantage of relationships, and resources. Thus, the second hypothesis is formulated:

H2: The enabling perception of the MCS has a direct and positive effect on organizational resilience.

\subsection{Psychological empowerment and organizational RESilience}

The literature does not provide conclusive evidence regarding the relationship between psychological empowerment and organizational resilience. Several studies have investigated these constructs isolated, and when investigated together they are restricted to individual resilience (e.g., Amanati, 2014). However, it is conjectured that individual resilience, as evidenced in the work environment, offers the ability to face situational, transformational, or adaptive adversities, which leads to organizational resilience (Linnenluecke, 2017). "Resilient individuals, as part of the entire organizational system, must be a positive factor for organizations to develop their resilience capacity" (Kantur \& Iseri-Say, 2012, p. 764).

Studies in the medical field (Larrabee et al., 2010; Besuner \& Bewley, 2017) have shown that empowerment affects resilience, and that each individual has an outcome in adverse contexts, in which individual and collective adaptation and advancement may happen (Brodsky \& Cattaneo, 2013). Empowerment is important for stimulating and managing change in organizations (Spreitzer, 1995). Individuals with psychological empowerment exhibit behavioral characteristics, such as concentration and initiative (Thomas \& Velthouse, 1990), which lead to organizational resilience.

More self-determined motivation, which results from the achievement of individuals' basic psychological needs (SDT), leads to more adaptive outcomes (Vallerand et al., 2008), elements necessary for resilience, which acts in the adoption of positive cognition and strategies of coping to reduce the influence of disruptive events. Empowerment helps the individual maintain a motivated posture, moderating the threat and stress inherent in hard times, while providing the resources and psychological strength needed to persevere (Spreitzer \& Doneson, 2005).

Larrabee et al. (2010) observed that employees will have greater resilience and job satisfaction and less situational stress when they receive psychological empowerment. Amanati (2014) found out that psychological empowerment plays an important role in predicting and increasing resilience and job satisfaction of employees. Empowered employees will engage in decision-making processes and may be able to generate creative solutions with greater authority and skill (Mallak, 1998), which will contribute to the organizational resilience.

Previous studies (Thomas \& Velthouse, 1990; Besuner \& Bewley, 2017) discuss the relationship between self-efficacy, resilience, and empowerment. Self-efficacy is related to effort, persistence, and perseverance, and empowerment has self-efficacy perceived as one of the intrapersonal factors (Zimmerman, 1995). Self-efficacy is also an essential element of resilience, as it provides motivation/confidence in the self-evaluation of one's own abilities, in regards to individual choices, how to complete tasks, how to solve problems, or how to plan actions to achieve an outcome (Bandura, 1986). Besuner and Bewley (2017) confirm the interactions of self-efficacy, psychological empowerment, individual resilience and leadership style with organizational resilience.

Empowered employees are recognized to have greater autonomy, which may reflect in greater impact at work, increased self-esteem, and self-efficacy, and a sense of control over their tasks 
BBR

17

218

and environment, which may contribute to change (Sun et al., 2012). When individuals feel empowered, proactive behaviors such as flexibility, persistence, and resilience emerge (Thomas $\&$ Velthouse, 1990). Interactions between psychological empowerment and organizational resilience are expected, as the first can provide motivational and cognitive support, so that the individual (Thomas \& Velthouse, 1990) feels more able to cope with and adapt to changes, and seeks to shape the work environment (Spreitzer, 1995). In this sense, the third hypothesis is formulated:

H3: Psychological empowerment positively influences organizational resilience.

Based on the hypotheses proposed, the conceptual model of the research is illustrated in Figure 1.

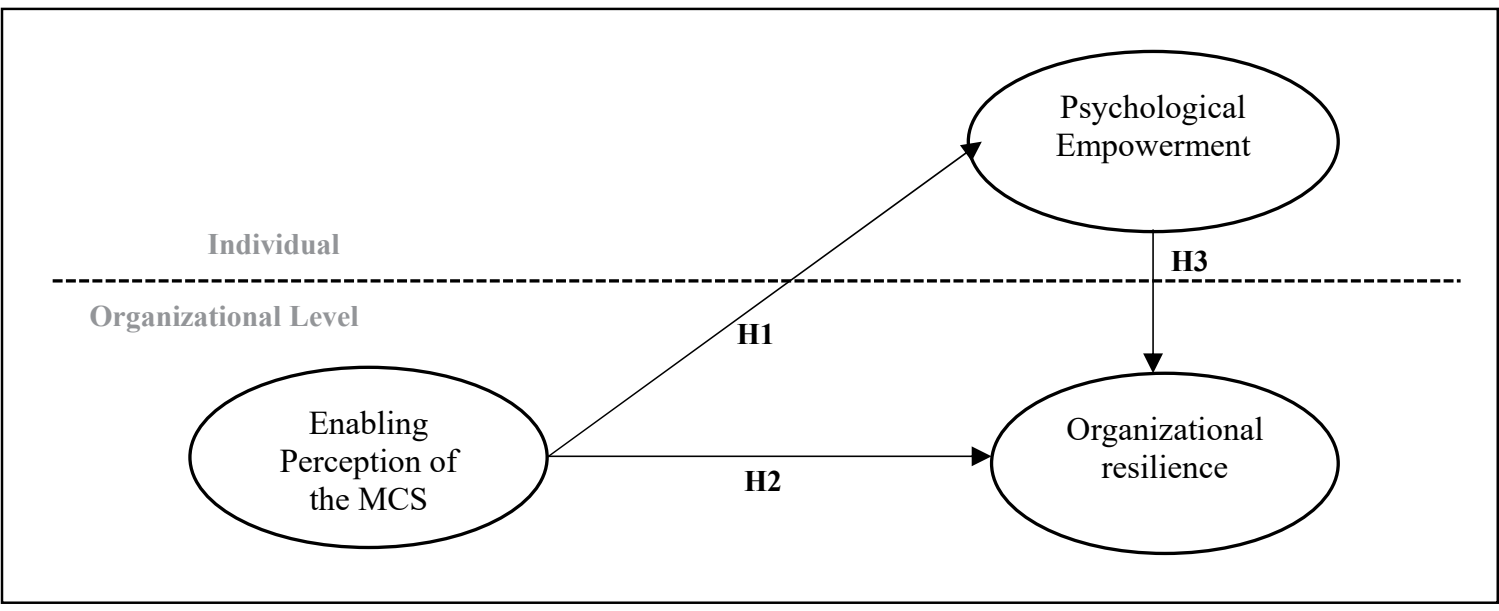

Figure 1. Conceptual model

Source: Prepared by the authors.

According to Figure 1, the study predicts that the enabling perception of the MCS positively influences empowerment $(\mathrm{H} 1)$ and organizational resilience $(\mathrm{H} 2)$, and that psychological empowerment positively affects organizational resilience $(\mathrm{H} 3)$. The enabling perception of the MCS is presumed to be able to generate feelings of autonomy, with individual reflexes, by giving voice and power to the employees, and by providing mechanisms to cope with adversities and changes, promoting a pro-social force with organizational reflexes. It is also assumed that, from the motivating involvement of the individual generated by their autonomy, positive behaviors that seek flexibility and persistence when facing the need for adaptations will be observed in the organization (Thomas \& Velthouse, 1990; Hall, 2008; Kantur \& Iseri-Say, 2012).

\section{METHODOLOGICAL PROCEDURES}

\subsection{SAMPLE SELECTION AND DATA COLLECTION}

A survey was conducted with managers of Brazilian companies that went through the process of company acquisitions from January 2016 to January 2017, according to the report Fusóes $e$ Aquisiçôes no Brasil (Mergers and Acquisitions in Brazil) prepared by PricewaterhouseCoopers (PwC Brasil). The selection of these companies is justified by the fact that the processes of company acquisition imply changes in the MCS, continuous negotiations, changes in organizational 
structure, and adaptations in both the acquiring and acquired companies (Jordão \& Souza, 2013). This requires the individuals and organizations involved to be resilient.

Thus, companies that acquired or were bought by others during this period were mapped. This mapping excluded foreign companies, as well as companies in the financial sector, as well as real estate and investment funds. In the end, there were 238 acquiring and / or acquired companies. The selected sample is due to the fact that resilience is linked to the organizations ability to respond to situations and adapt in terms of creating new solutions (Akgün \& Keskin, 2014).

We made contact with the managers of these companies through the social network LinkedIn, using a Premium account, by searching the terms "manager" and "coordinator" in the companies selected. After this process, an invitation was sent to the managers to join the social network created on LinkedIn, in order to answer the survey, as at that point it was not possible to send the link with the survey instrument. At this stage, it was not possible to cover all the mapped companies, since not all of them had people registered on the LinkedIn platform. The 1,027 managers who accepted the invitation were sent the link to the survey instrument via Survey Monkey. From March to April 2017, 161 complete answers were returned, which makes up the final study sample.

From that total, $78(48.4 \%)$ reported that their organization made acquisitions of other business units/companies. The majority of them (53.8\%) reported that their department had few changes because of these transactions. Others (20.5\%) reported that their company was bought by another. Most of them (54.5\%) reported that their department/organizational area had many changes after the transaction. Others (22.4\%) reported that their business unit and/or company was acquired/bought by a company and that their organization also made acquisitions of other business units/companies. Most of them reported that their organizational area underwent several changes with the operations; 9 didn't know how to answer to this question and 5 did not answer this question.

The demographic characteristics of the respondents indicated that most are male $(92.5 \%)$, with an average age of 41.1 (standard deviation of 7.70), have a specialization course or MBA (67.1\%). They had worked in their respective organizations for an average of 9.8 years (standard deviation of 8.50) and work as manager/coordinator for an average of 4.5 years. Respondents are responsible for various organizational areas/departments, with emphasis on commercial, information technology, sales, production, controllership, maintenance, and supplies.

In order to test the response validity, the averages of the first 10 responses were compared to the last 10 as a proxy for non-response bias, and there were no statistically significant differences between the two groups in all constructs ( $p$-values between 0.105 and 0.702 ). This criterion was adopted by Mahama and Cheng (2013) and is called first last. Another comparison was made between the first 77 respondents and the last 84 , who needed reminders to complete the survey (Wåhlberg \& Poom, 2015). The results of the mean tests did not indicate significant differences at the significance level of $5 \%$ between the groups ( $p$-values between 0.08 and 0.69 ).

\subsection{Measurement of ReSEARCH CONSTRUCTS}

The research constructs (enabling perception of the MCS, psychological empowerment and organizational resilience) were measured by multiple items, with a five-point Likert scale, ranging from strongly disagree to totally agree.

The enabling perception of the MCS was measured based on eight items, in which respondents indicated their degree of agreement with the statements regarding the MCS of their organizations. 
BBR

17

220

The assertions were based on theoretical definitions and descriptions, as well as adaptations of previous studies, such as the ones conducted by Chapman and Kihn (2009), Hartmann and Maas (2011) and Mahama and Cheng (2013). For example, the assertion "I realize that MCSs are used to help people deal directly with the inevitable contingencies of their work", was written based on the propositions of Adler and Borys (1996) and Ahrens and Chapman (2004). The statement "I realize that MCSs are designed with the purpose of allowing people in the company to work more efficiently" was taken from the study by Mahama and Cheng (2013). As for reliability, this construct has a Cronbach's alpha of 0.939 and a KMO of 0.930 , which indicates the constructs internal consistency. Exploratory factor analysis confirmed that these assertions correspond to a single construct, representing $70.17 \%$ of the total variance explained.

In the research instrument, it was clarified that MCS contemplates all instruments and systems that managers use to ensure that individuals' behaviors and decisions are consistent with the organization's objectives and strategies (Merchant \& Van der Stede, 2007). It was exemplified that MCS includes information systems, budgets, and performance evaluation systems, among others. In the literature, MCS is conceptualized in different ways (Ferreira \& Otley, 2009), some definitions contain overlaps, while others are distinct (Malmi \& Brown, 2008. In this research, we adopted the concept of MCS as established by Malmi and Brown. (2008, p. 290), which is understood as a set of "systems, rules, practices, values and other management activities implemented to direct employee's behavior", in pursuit of organizational objectives.

In psychological empowerment, the respondents indicated their degree of agreement with the statements presented. This construct was composed of 12 assertions from the study conducted by Spreitzer (1995), three for each dimension (meaning, competence, self-determination, and impact), and presented an overall Cronbach's alpha of 0.849. Exploratory factor analysis grouped the assertions into the four dimensions proposed by Spreitezer (1995), which represented 75.09\% of the total variance explained and a KMO of 0.797 . Some examples of statements presented would be: "The work I do is very important to me"; and "I master the skills necessary to do my job".

The organizational resilience was investigated through 15 assertions proposed by Akgün and Keskin (2014), in which respondents indicated their degree of agreement with the assertions regarding the environment of their organizations. Some examples of such statements are: "When facing turbulence, we are able to follow a course of action considerably different from what is set as the norm"; and "We undertake actions and investments before they are necessary to ensure that we will be able to benefit in situations that may arise". Exploratory factor analysis grouped these assertions into two groups, whose total variance explained was $61.56 \%$. Cronbach's overall alpha for the organizational resilience construct was 0.921 , the dimension called improvised agility, with six assertions, 0.868 , and the behavioral preparation dimension, with nine assertions, 0.911 .

\subsection{Procedures for data analysis}

In order to analyze the data and test the hypotheses, the Structural Equations Modeling (SEM) technique estimated from Partial Least Squares (PLS) were used with the aid of SmartPLS software (version 3). According to Hair Jr., Hult, Ringle, and Sarstedt (2013), the PLS-SEM technique, also called PLS path modeling, efficiently estimates coefficients that maximize the R2 values of endogenous constructs. It is considered the ideal method when research seeks theory development and to explain the variation of the dependent variables when examining the model (Hair Jr. et al., 2013). The authors point out that PLS-SEM can be applied to a wide variety of research situations and models, whether they are formative reflective, or single item constructs. 
The psychological empowerment and organizational resilience constructs were modeled as second-order, reflexive formative, constructs (Type II) (Chin, 1998a; Becker, Klein \& Wetzels, 2012). Type II models are those in which each dimension, or first -order (lower order) constructs measure phenomena that do not necessarily share a common cause, but which together reflect in the broad construct (Chin, 1998a). Analyses of second order constructs can offer greater generality, amplitude, and simplicity to the results, providing greater inferences in the reduction of complex phenomena. This practice allows greater theoretical parsimony than isolated investigations of its dimensions (Edwards, 2001), as it helps to overcome weaknesses (missing areas) of each individual index (Becker et al., 2012).

In this study, following the recommendations of Edwards (2001), care was taken to include and analyze, in the same model, the dimensions and the multidimensional constructs (secondorder constructs), which allow for conducting reflective tests associated with these constructs and their respective dimensions, as well as specific tests for formative validations. The model was analyzed in the approach of repeated indicators in the second-order constructs, to identify the individual reflexes of the first order constructs in the higher-order construct. A two-stage approach was also adopted for structural validation in order to help accurately estimate the path coefficients of higher-order constructs.

In addition to the exploratory factor analysis (EFA), confirmatory factor analysis (CFA) was performed using the software Amos, initially from the isolated constructs and then with the second-order model, in addition to the complete model. The following indexes were used: (i) of adjustments - Chi-square $\left(\chi^{2}\right)$, GFI (Quality of Fit Index), RMR (Root Mean Square Residue), RMSEA (Root Mean Square Error of Approximation); (ii) incremental adjustment - NFI (Normed Fit Index) and AGFI (Adjusted Goodness of Fit Index); and (iii) parsimonious - Normalized Chi-square $\left(\chi^{2} / \mathrm{DF}\right)$.

Information on independent and dependent variables were collected from the same respondents, which may cause a Common Method Bias (Podsakoff, Mackenzie \& Podsakoff, 2012). In order to minimize the effects of such a bias, procedural measures recommended by these authors were adopted: (i) the anonymity of the respondents was guaranteed; (ii) guidance was provided that there were no right or wrong answers and that respondents should answer questions based on the present; (iii) the research statements were written with simple language and clarification of terms, when necessary (e.g. MCS); and (iv) balance was made in the presentation of the questions. The impact of the common method bias was also evaluated using a post hoc approach, such as Harman's single factor test (Podsakoff et al., 2012). The results indicated that the common method bias is not a concern, as several factors with eigenvalues greater than 1 were identified, accounting for $69.3 \%$ of the total variance, and no factor represented almost the entire variance (Podsakoff et al., 2012).

\section{DESCRIPTION AND ANALYSIS OF DATA}

Descriptive and exploratory factor analyses (EFA) were performed with the help of SPSS (version 22). Subsequently, confirmatory factor analyses (CFA) and structural equation modeling (SEM-PLS) were performed to validate the measurement models and structural model. In the CFAs for psychological empowerment and organizational resilience, their interactions were initially observed as first-order constructs, then as second-order constructs. Subsequently, the measurement model was investigated with all constructs, first order (enabling perception) and second order (empowerment and resilience). Table 1 presents the main indexes of these analyses. 
BBR

17

222

Table 1. Confirmatory Factor Analysis of the model constructs

\begin{tabular}{ccccccc}
\hline \multirow{2}{*}{ Indexes } & $\begin{array}{c}\text { Enabling } \\
\text { Perception MCS }\end{array}$ & \multicolumn{2}{c}{$\begin{array}{c}\text { Psychological } \\
\text { Empowerment }\end{array}$} & \multicolumn{2}{c}{ Organizational Resilience } & Complete \\
\cline { 3 - 6 } & & 1st Order & 2nd Order & 1st Order & 2nd Order* & measurement model* \\
\hline$\chi^{2}$ & 32.031 & 60.681 & 70.181 & 180.782 & 105.725 & 711.292 \\
$\mathrm{df}$ & 17 & 48 & 53 & 76 & 71 & 513 \\
$\chi^{2} / \mathrm{df}$ & 1.884 & 1.264 & 1.475 & 2.379 & 1.489 & 1.387 \\
$\mathrm{p}$-value & 0.015 & 0.103 & 0.014 & 0.000 & 0.005 & 0.000 \\
RMSEA & 0.074 & 0.041 & 0.054 & 0.093 & 0.055 & 0.049 \\
RMR & 0.034 & 0.022 & 0.051 & 0.050 & 0.038 & 0.060 \\
CFI & 0.984 & 0.985 & 0.970 & 0.922 & 0.974 & 0.942 \\
GFI & 0.951 & 0.904 & 0.929 & 0.871 & 0.918 & 0.807 \\
AGFI & 0.895 & 0.910 & 0.896 & 0.822 & 0.879 & 0.776 \\
NFI & 0.968 & 0.933 & 0.914 & 0.874 & 0.926 & 0.821 \\
\hline
\end{tabular}

Note: $\mathrm{n}=191 .{ }^{*}$ The error values for these models were adjusted.

For the constructs empowerment and organizational resilience, there was an improvement in the model when it was analyzed as a second-order construct, being significant and having a good index of model adequacy. The results show superiority of the reflective formative model of second order. For the constructs empowerment and organizational resilience the models of second order were significant, with RMSEA indicating a good fit (less than or equal to 0.06) or an excellent fit (less than 0.05) (Hu \& Bentler, 1999). Using the two-index strategy proposed by $\mathrm{Hu}$ and Bentler (1999), which suggests that a model is acceptable if it satisfies one of the two condition pairs, we have: RMSEA $<0.06$ and CFI, TLI or RNI $>0.95$; or RMSEA $<0.06$ and SRMS $<0.08$. Both constructs meet these conditions, indicating acceptable models.

The complete measurement model, composed of all the constructs, presented significant statistics of good fit, with some indexes indicating good fit of the model. RMSEA values indicate an excellent model fit (less than 0.05) (Hu \& Bentler, 1999). It satisfies one of the conditions of $\mathrm{Hu}$ and Bentler (1999), of RMSEA $<0.06$ and SRMS $<0.08$, which implies the adherence of an acceptable model. It presented a CFI lower than 0.95 , but the CFI value $(0.942)$ can be considered acceptable $(>0.90)$ and indicate a good fit (Schreiber et al., 2006). The model also presented a GFI index below the acceptable range $(\geq 0.90)$, however, it is believed to be an artifact with large degrees of freedom in relation to the sample size and number of estimated parameters.

Based on the CFAs, it is inferred that the model is adequate to proceed with the evaluations of the structural equation model.

\subsection{Measurement model}

As this study refers to a reflective-formative model, type II, composed of reflective indicators, lower-order components (dimensions) and higher-order components, it adopted measurements both for reflective models and for formative models, as well as the approach of repeated indicators. According to Hair Jr. et al. (2013) the concepts of internal consistency and reliability are inadequate for formative models as they are considered error free, as it is inappropriate to evaluate the measurement model using reflective measurement model criteria such as convergent and discriminant validity. Instead, it is recommended to establish the content validity, since higher- 
order (second-order) constructs do not refer to a question of causality, but of the hierarchical latent variable nature, as the concept or construct does not exist without the constructs corresponding to their dimensions (Becker et al., 2012).

According to Hair Jr. et al. (2013), unlike the reflective measurement models, which assess the validity (convergent and discriminant) and reliability (internal and composite) of construct measurements, the formative measurement models assess: (1) the validity convergence of formative measurement models; (2) collinearity problems; and (3) the importance and relevance of formative indicators. Thus, the evaluations related to the reflexive constructs were performed (Table 2).

Table 2. Results of the measurement model and descriptive statistics

\begin{tabular}{lcccccccc}
\hline Constructs & 1 & 2 & 3 & 4 & 5 & 7 & 8 & VIF \\
\hline 1.Enabling & 0.838 & & & & & & & 1.844 \\
2.Meaning & $0.279^{* *}$ & 0.892 & & & & & & 1.356 \\
3.Competence & $0.207^{* *}$ & $0.266^{* *}$ & 0.836 & & & & & 1.264 \\
4. Self determination & $0.336^{* *}$ & $0.265^{* *}$ & $0.304^{* *}$ & 0.849 & & & & 1.340 \\
5.Impact & $0.404^{* *}$ & $0.489^{* *}$ & $0.287^{* *}$ & $0.442^{* *}$ & 0.876 & & & 1.631 \\
7. Improvised Agility & $0.607^{* *}$ & $0.362^{* *}$ & $0.180^{*}$ & $0.333^{* *}$ & $0.304^{* *}$ & 0.771 & & 2.498 \\
8. Behavioral Preparation & $0.630^{* *}$ & $0.428^{* *}$ & $0.192^{*}$ & $0.324^{* *}$ & $0.308^{* *}$ & $0.753^{* *}$ & 0.779 & 2.654 \\
AVE & 0.701 & 0.795 & 0.699 & 0.721 & 0.768 & 0.595 & 0.607 & \\
Composite Reliability & 0.949 & 0.921 & 0.874 & 0.886 & 0.908 & 0.911 & 0.925 & \\
Cronbach's Alpha & 0.939 & 0.871 & 0.785 & 0.806 & 0.849 & 0.885 & 0.907 & \\
Mean & 3.42 & 4.57 & 4.55 & 3.90 & 4.20 & 3.39 & 3.46 & \\
Standard Deviation & 1.10 & 0.71 & 0.58 & 0.82 & 0.84 & 1.03 & 1.03 & \\
\hline
\end{tabular}

Note: The diagonal elements are the square roots of the average variance extracted (AVE). Off-diagonal elements are the correlations between the constructs. Significant at the level of ${ }^{* *} 0.01 \mathrm{e}^{*} 0.05$.

Source: Research data.

Table 2 shows convergent validity based on the average variance extracted (AVE), as its coefficients are above 0.50 (Hair Jr. et al., 2013), indicating that the external loads of the indicators and how the latent variables correlate with their constructs is appropriate. There is also an indication that the model is adequate for the reliability of responses, as Cronbach's alpha (internal reliability) and composite reliability presented values greater than 0.70 . Discriminant validity was also attested, evaluated through the square root of the AVE (diagonal value in bold) (Fornell \& Larcker, 1981) and through the cross-load criterion (Chin, 1998b). Both attest to the ability of each construct to differ from the others and to capture phenomena unique to the proposed model.

When analyzing Pearson's correlation coefficients, it is observed that all constructs have positive and significant associations with each other. To ensure the absence of correlations that indicate the presence of multicollinearity, the Variance Inflation Factors (VIF) was analyzed in the SmartPLS, where the highest VIF value was 2.654, indicating the absence of multicollinearity between the latent variables since VIF values must lower than 5, according to the precepts of Hair Jr. et al. (2013).

In the evaluation of the formative models of the constructs psychological empowerment and organizational resilience, the convergent validity for both constructs was confirmed. Convergent validation for formative cases seeks to recognize the extent to which each indicator or construct is actually able to provide a contribution to the formative construct (Hair Jr. et al., 2013). It 
BBR

17

224

was observed that the strength of the path coefficients, the first-order constructs, indicates the validity of the formative constructs with $\mathrm{R}^{2}$ of 1 and significance $(\mathrm{p}<0.000)$, which indicates that the second-order constructs are perfectly predicted by the dimensions as advocated in theory. Psychological empowerment is explained by its dimensions in the following measures: competence 0.248 , self-determination 0.330 , impact 0.398 and meaning 0.407 ; while organizational resilience in the following measures: improvised agility 0.486 and behavioral preparation 0.582 .

No multicollinearity problems were identified in the model, since the VIF of all constructs was greater than 0.20 and lower than 5.0 (Hair Jr. et al., 2013). Finally, in the test to measure the relevance of the indicators, or lower-order constructs, for the higher-order construct, observed by external weights, by means of bootstrapping (other weights), significance was identified for all indicators with their respective reflective and formative constructs.

From the results of the reflective and formative measurement model, all constructs were considered reliable and valid, which supports their suitability for the analysis of the structural model.

\subsection{Structural Model}

In the analysis of the structural model, the two-stage approach was used to help accurately estimate the path coefficient and to examine the research hypotheses. Thus, the Bootstrapping technique was performed to assess the level of significance between the relationships of the constructs, with 5,000 subsamples and 5,000 interactions, bias-corrected and accelerated confidence interval, and a one-tailed test at a significance level of 5\% (Hair Jr. et al., 2013). The path values (path), t-value, $\mathrm{p}$-value and R2 of each relationship were obtained from Bootstrapping. The analyses of the Blindfolding module (for F2 and Q2) are not procedures applied to formative endogenous constructs (Hair Jr. et al., 2013), and were not adopted due to limitations in interpreting the two-stage approach. Figure 2 shows the effects of paths between the constructs and the validation of the hypotheses proposed.

The interactions between the variables indicate that the enabling perception of the MCS was positively and significantly associated with psychological empowerment $(0.438, \mathrm{p}<0.000$, $\mathrm{t}$-value 5.622), and has a moderate $(0.192)$ explanatory power $\left(R^{2}\right)$ between the variables. Thus, there is support for confirming the hypothesis $\mathrm{H} 1$, that the enabling perception of MCS positively and significantly influences psychological empowerment. This result confirms that, when employees perceive more flexible and autonomous MCSs, that favor interpersonal interactions and generate feelings of competence, they tend to feel more empowered by the organization.

There was also a positive and significant association $(0.662, \mathrm{p}<0.000$, $\mathrm{t}$-value 11.221$)$ in the relationship between the enabling perception of the MCS and organizational resilience, which confirms hypothesis $\mathrm{H} 2$, that the enabling perception of the MCS has a direct effect on organizational resilience. This indicates that the enabling settings of the MCS can provide the capability of coping with adverse situations, uncertainties and changes.

The interaction between psychological empowerment and organizational resilience also shows a positive and significant relationship $(0.218, \mathrm{p}<0.001$, $\mathrm{t}$-value 3.303$)$. Therefore, there is support for confirming $\mathrm{H} 3$ that psychological empowerment directly and positively impacts organizational resilience. This interaction suggests that psychological and intrapersonal support is required for organizations to adapt, cope with, or resist a given situation.

Altogether, the antecedents enabling perception and psychological empowerment have a relevant effect on explaining the influence on the resilience variable $\left(\mathrm{R}^{2} 0.476\right)$. This result indicates that 


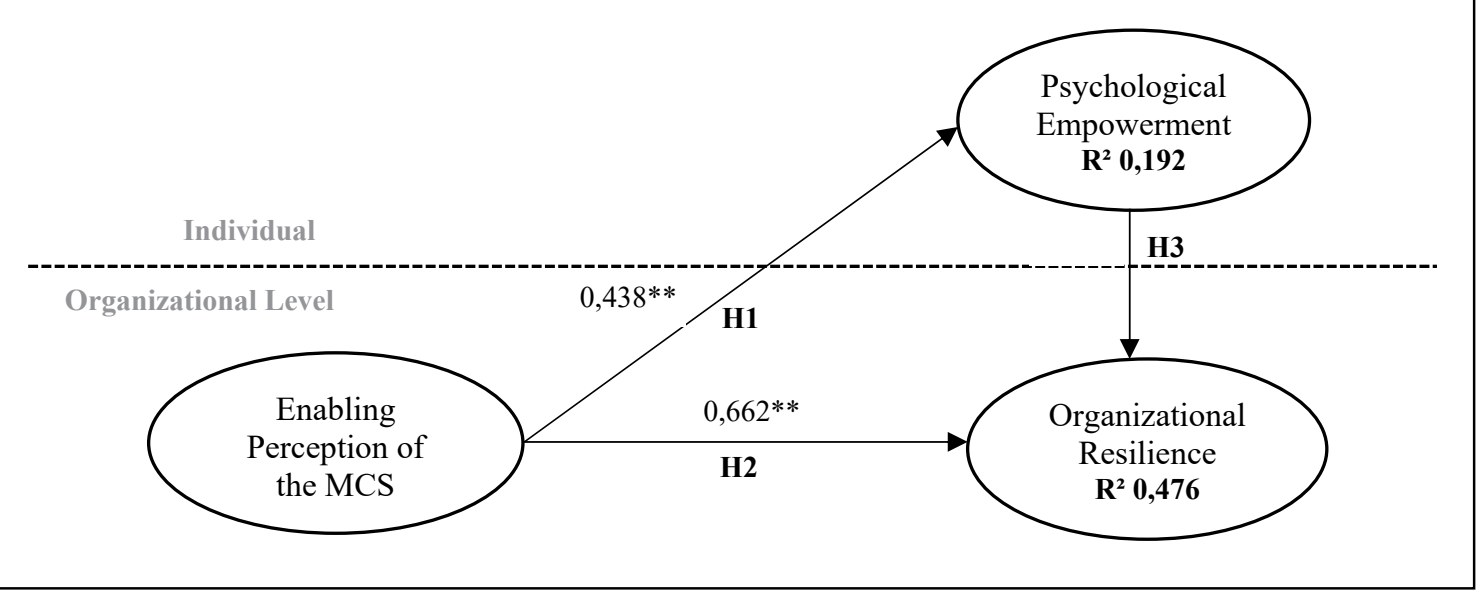

Figure 2. Validation of the structural model

Note: Significance level of ${ }^{*} \mathrm{p}<0.001 ;{ }^{* *} \mathrm{p}<0.000$.

Source: Prepared by the authors.

organizational resilience can be influenced by particularities of the MCS (organizational level) and by psychological behaviors (individual level).

\subsection{Discussion OF THE RESUlTS}

When examining the effects of the enabling perception of the MCS on psychological empowerment and organizational resilience, the results supported $\mathrm{H} 1$ by demonstrating that the enabling perception of the MCS is associated with psychological empowerment, suggesting that the characteristics of the MCS affect manager's motivation in relation to their work environment. This signals the behavioral implications of the MCS in organizations and is consistent with what is proposed in the enabling logic of Adler and Borys (1996), it is intended to motivate, direct and influence the individuals' actions, promoting control in the organization. The results of this study support that enabling MCSs are designed to enhance users' capabilities and leverage their skills and intelligence (Free, 2007).

The association between the enabling perception of the MCS and empowerment indicates that, when MCSs are designed to increase people's knowledge of their role in the organization where sharing information and experimentation are encouraged, individuals feel more motivated to do their work. This leads to the proposition that flexible MCSs increase managers' sense of purpose in conducting their activities (Adler \& Borys, 1996). These results can be explained through the lens of the Self-Determination Theory, as the enabling perception of the MCS supports the autonomy of the employees, promoting autonomous motivation (Gagne \& Deci, 2005). It signals that empowering managerial behaviors can satisfy basic human needs (autonomy, competence, and relationships) (Ryan \& Deci, 2000). Therefore, the organizational environment influences the cognitions of empowerment (Thomas \& Velthouse, 1990).

The survey results also support hypothesis $\mathrm{H} 2$, pointing out that the enabling perception of the MCS reflects in the capacity of organizational resilience. This converges with the understanding that the enabling MCSs encourage organizations to deal with adverse contingencies (Adler \& Borys, 1996). The enabling MCSs assist organizations in the process of absorbing changes and regaining balance after any temporary disruption (e.g. acquisitions of companies) when: they 
BBR

17

226

provide visibility into internal activities; they allow changes in procedures when facing new opportunities; they enable modifications of functionality; they share a broad set of information; they prioritize learning and flexible relationships; and they encourage dialogue and experimentation (Free, 2007; Wouters \& Wilderom, 2008).

Resilience may be increased or reduced depending on the degree of rigidity in the design and use of the MCS (Ignatiadis \& Nandhakumar, 2007). Systems that are complex, hierarchically organized, and have rigid parameters can be vulnerable to small and unforeseen disturbances. Alternatively, interactive systems may offer equivalent functionality with greater capability of resiliency (Fiksel, 2003). The research results make it possible to infer that systems designed in accordance with enabling logic allow organizations to face turbulence and unexpected events due to their strategic awareness and operational management.

The evidence of the positive and significant relationship between psychological empowerment and organizational resilience supports the hypothesis $\mathrm{H} 3$. This signals that individual motivation is capable of generating pro-social behaviors and more positive and adaptive outcomes (Mallak, 1998; Vallerand et al., 2008). And, attitudes that encourage organizational behaviors of flexibility, agility, and adaptation to surviving in change able conditions can foster greater resilience (Kantur \& Iseri-Say, 2012). It is inferred that functional empowerment plays an important role in predicting and increasing the organizational resilience (Amanati, 2014) by offering elements that provide the psychological resources needed to persevere (Spreitzer \& Doneson, 2005).

Therefore, the organizations need to engage individuals and assign value to a work purpose (meaning) (Thomas \& Velthouse, 1990) in order to deal with unfamiliar situations and develop alternatives for coping with new events (Linnenluecke, 2017). When the individual keeps intact his or her involvement, sense of purpose, and identification with his or her activities, regardless of the burden of the adaptive process, there will be organizational resilience. It is argued that greater organizational resilience may also be linked to the managers' perception of autonomy (selfdetermination), as they are free to make decisions about work methods, pace and efforts in their activities. These actions can produce greater flexibility, creativity, initiative and self-regulation, and influence learning, interest in activity and resilience when facing adversity (Deci \& Ryan, 1985).

In general, the evidenced results of the relationship between psychological empowerment and organizational resilience reveal the importance of the work perceived by the individual and the autonomy granted. Both make individuals engage to find unconventional answers to the challenges presented. These findings indicate that when individuals feel that their work activities are meaningful to them, they can follow a course of action that differs from what is considered the norm (Akgün \& Keskin, 2014). Concerns about performing tasks, freedom, and the power granted to managers favors them to cope better with turbulence and adapt to changes such as redistribution of functions and positions in the case of company acquisitions.

\section{FINAL CONSIDERATIONS}

This study examined the effects of the enabling perception of the MCS on psychological empowerment and organizational resilience. In general, the results indicated that the enabling perception of the MCS has direct implications for psychological empowerment and organizational resilience. Additionally, it was discovered that psychological empowerment positively influenced an organization's resilience. 


\subsection{TheORETICAL IMPLicaTions}

The contribution of this study to the literature lays on the examination of how individual (empowerment) and organizational (resilience) behaviors can be influenced by the enabling perception of the MCS. The study broadens the discussion of the MCS' role in psychological empowerment, analyzed as a multidimensional construct (Zimmerman, 1995), of second order (Spreitzer, 1996). The literature has presented divergent results about the role of MCS in the empowerment of managers regarding the effects of their dimensions. Evidence suggests that the enabling perception of MCS can enhance managers' knowledge of workplace operations and business strategies, and strengthen their ability to influence behaviors and outcomes (Hall, 2008).

The study also contributes to reduce the research gap on the effects of the MCS on organizational resilience, previously focused on information systems. For Annarelli and Nonino (2016), organizational resilience can be considered a matter under development. Despite the growing number of researches, some elements are not yet clearly defined, such as the variables that may impact on it. Linnenluecke (2017) mentions that it has not yet been fully explored whether certain organizational resources, capabilities or structures promote resilience and how they need to be configured to succeed. This study contributes empirically to this gap by providing evidence that the enabling perceptions of the MCS influence the capability of organizational resilience.

Another theoretical contribution of this study refers to the discussions and interactions between psychological empowerment and organizational resilience, since this relationship is not so elucidated in studies on management, more in the health area. Furthermore, resilience is commonly explored as a construct of individual scope, unlike this study, where, while recognizing that individual resilience may play a motivational role, the collective actions create a broader resilient response (Linnenluecke, 2017).

\subsection{Practical implications}

The survey results also have practical implications for organizations by demonstrating that the enabling perception of the MCS has the ability to intrinsically motivate its managers by broadening the work purposes (meaning), strengthening beliefs of the ability to perform it (competence), autonomy to act (self-determination) and influence outcomes (impact). Therefore, a MCS that reduces role ambiguity favors an environment of participatory unity, maintains sociopolitical support and provides resources, tends to facilitate the empowerment of its employees (Spreitzer, 1995).

The study provides evidence that the enabling MCSs positively influence organizational resilience. Organizations are constantly exposed to turbulence and unexpected events, which requires resilience. Thus, they will have to take proactive measures and create new business opportunities to deal with these adversities (Annarelli \& Nonino, 2016). This implies systems capable of contributing to this process of adaptation, modification, coping, and reinvention. This research provides insights that the enabling configurations of the MCS may favor this process because they are flexible systems that allow for innovation, experimentation and learning.

Another contribution of this study refers to the implications of empowering individuals with organizational resilience, signaling the relevance of managers' perception of autonomy and involvement, so that they contribute to the resilience of the organizations. For empowerment to take place, MCSs must be designed to provide managers with the information and knowledge they need, and to clarify how their roles fit within the scope of their organizational goals. 


\subsection{LIMITATIONS AND SUGGESTIONS FOR FUTURE RESEARCH}

This study shares the usual limitations of cross-sectional research, such as common method bias, self-assessment of participants, halo effect, and response rates. Relationships between the variables proposed in theoretical-empirical studies were identified. However, data and causal relationships should be interpreted with parsimony, since the results show only statistical associations between the model paths (Appuhami, 2017). Alternative research methods, such as longitudinal case studies, may provide more concise information about the proposed relationships.

It is noteworthy that the constructs were measured on a multidimensional scale, making subordinates' self-assessments less susceptible to a halo effect, with responses considered as consistent. In addition, the procedural measures related to the research instrument and the application of Harman's single factor test (Podsakoff et al., 2003) signaled that the common method bias is not a problem in this study.

The survey respondents are managers of Brazilian companies that have gone through the process of company acquisitions. However, the study does not separately analyze whether acquired or acquiring companies are, in fact, resilient. In addition, about $20.5 \%$ of the respondents reported that their company was bought by another company. In these situations, the perception of respondents at the time of answering the survey may have been different, as these managers may have formulated their responses by thinking throughly about the organizational environment of the former company or that of the acquirer.

The study focused on the enabling perceptions of the MCS. Studies in the accounting area (e.g. Ahrens \& Chapman, 2004; Burney et al., 2017) have shown evidence that the MCS have both enabling and coercive characteristics. Future research may investigate the effects of coercive and enabling controls on other individual (e.g. commitment to goals) and organizational (e.g. innovation) outcomes. Other taxonomies of the MCS can be used to explore the relationship between MCS, psychological empowerment, and organizational resilience. Possible consequences of organizational resilience were not addressed either, since the research focused on the antecedents.

Another limitation is that the respondents may have had different understandings of what constitutes and characterizes an MCS. Although a definition and examples were provided in the research instrument, respondents may have interpreted the concept differently and/or focused on a particular instrument (e.g. performance evaluation) at the time they were analyzing the assertions and answering the questionnaire of the study.

\section{REFERENCES}

Adler, P.S., \& Borys, B. (1996). Two types of bureaucracy: Enabling and coercive. Administrative Science Quarterly, 41(1), 61-89.

Ahrens, T., \& Chapman, C.S. (2004). Accounting for flexibility and efficiency: A field study of management control systems in a restaurant Chain. Contemporary Accounting Research, 21(2), 271-301.

Akgün, A.E., \& Keskin, H. (2014). Organizational resilience capacity and firm product innovativeness and performance. International Journal of Production Research, 52(23), 6918-6937.

Amanati, S. (2014). Investigating influence of psychological empowerment on resiliency and job satisfaction among employees of insurance firms. Research Journal of Recent Sciences, 3(11), 1-5. 
Annarelli, A., \& Nonino, F. (2016). Strategic and operational management of organizational resilience: Current state of research and future directions. Omega, 62(1), 1-18.

Appuhami, R. (2017). Exploring the relationship between strategic performance measurement systems and managers' creativity: the mediating role of psychological empowerment and organisational learning. Accounting \& Finance, 1-33.

Bandura, A. (1986). Social foundations of thought and action: a social cognitive theory. Englewood Cliffs: Prentice Hall.

Barasa, E., Mbau, R., \& Gilson, L. (2018). What is resilience and how can it be nurtured? A systematic review of empirical literature on organizational resilience. International Journal of Health Policy and Management, 7(6), 491-503.

Becker, J., Klein, K., \& Wetzels, M. (2012). Hierarchical latent variable models in PLS-SEM: guidelines for using reflective-formative type models. Long Range Planning, 45(5), 359-394.

Besuner, P., \& Bewley, L. (2017). Leadership attributes and behaviors as predictors of organizational resilience in academic health care systems. International Journal of Economics, Business and Management Research, 1(2), 167-188.

Beuren, I.M., \& Santos, V. (2019). Sistemas de controle gerencial habilitantes e coercitivos e resiliência organizacional. Revista Contabilidade \& Finanças, 30(81), 307-323.

Brodsky, A.E., \& Cattaneo, L.B. (2013). A transconceptual model of empowerment and resilience: Divergence, convergence and interactions in kindred community concepts. AmJ Community Psychol, 52(3-4), 333-346.

Burney, L.L., Radtke, R.R., \& Widener, S.K. (2017). The intersection of "bad apples" "bad barrels," and the enabling use of performance measurement systems. Journal of Information Systems, 31(2), 25-48.

Chapman, C.S., \& Kihn, L.A. (2009). Information system integration, enabling control and performance. Accounting, Organizations and Society, 34(2), 151-169.

Chin, W.W. (1998a). Issues and opinion on structural equation modeling, MIS Quarterly, 22(1), vii-xvi.

Chin, W.W. (1998b). The partial least squares approach for structural equation modeling. In: Marcoulides, G.A. (Ed.), Modern methods for business research (p. 295-336). New Jersey: Lawrence Erlbaum Associates.

Deci, E.L., \& Ryan, R.M. (1985). Intrinsic motivation and self-determination in human behavior. New York: Plennum Press.

Edwards, J.R. (2001). Multidimensional constructs in organizational behavior research: An integrative analytical framework. Organizational Research Methods, 4(2), 144-192.

Ferreira, A., \& Otley, D. (2009). The design and use of performance management systems: An extended framework for analysis. Management Accounting Research, 20(4), 263-282.

Fiksel, J. (2003). Designing resilient, sustainable systems. Environmental Science \& Technology, 37(23), 5330-5339.

Fornell, C., \& Larcker, D.F. (1981). Structural equation models with unobservable variables and measurement error: Algebra and statistics. Journal of Marketing Research, 18(3),382-388

Free, C. (2007). Supply-chain accounting practices in the UK retail sector: Enabling or coercing collaboration? Contemporary Accounting Research, 24(3), 897-933. 
BBR

17

Gagne, M., \& Deci, E.L. (2005). Self-determination theory and work motivation. Journal of Organizational Behavior, 26(4), 331-362.

Hair, Jr., J.F., Hult, G.T.M., Ringle, C. \& Sarstedt, M. (2013). A primer on partial least squares structural equation modeling (PLS-SEM). USA: Sage Publications.

Hall, M. (2008). The effect of comprehensive performance measurement systems on role clarity, psychological empowerment and managerial performance. Accounting, Organizations and Society, 33(1), 141-163.

Hartmann, F.G., \& Maas, V.S. (2011). The effects of uncertainty on the roles of controllers and budgets: an exploratory study. Accounting and Business Research, 41(5), 439-458.

Hempel, P.S., Zhang, Z.X., \& Han, Y.L. (2012). Team empowerment and the organizational context: Decentralization and the contrasting effects of formalization. Journal of Management, 38(2), 475-501.

Hu, L., \& Bentler, P.M. (1999). Cutoff criteria for fit indexes in covariance structure analysis: Conventional criteria versus new alternatives. Structural Equation Modeling. A Multidisciplinary Journal, 6(1), 1-55.

Ignatiadis, J., \& Nandhakumar, J. (2007). The impact of enterprise systems on organizational resilience, Journal of Information Technology, 22(1), 36-43.

Jordão, R.V.D., \& de Souza, A.A. (2013). Aquisição de Empresas como fator de mudança no sistema de controle gerencial: uma análise estratégica sob a perspectiva da Teoria Contingencial. Revista Universo Contábil, 9(3), 75-103. doi:10.4270/ruc.2013323

Kantur, D.Z. \& Iseri-Say, A. (2012). Organizational resilience: A conceptual integrative framework. Journal of Management \& Organization, 18(6), 762-773.

Larrabee, J.H., Wu, Y., Persily, C.A., Simoni, P.S., Johnston, P.A., Marcischak, T.L., Mott C.L., \& Gladden, S.D. (2010). Influence of stress resiliency on RN job satisfaction and intent to stay. Western Journal of Nursing Research, 32(1), 81-102.

Lengnick-Hall, C.A. Beck, T.E. (2005). Adaptive fit versus robust transformation: How organizations respond to environmental change. Journal of Management, 31(5), 738-757.

Lengnick-Hall, C.A., Beck, T.E. \& Lengnick-Hall, M.L. (2011). Developing a capacity for organizational resilience through strategic human resource management. Human Resource Management Review, 21(3) 243-255.

Limnios, E.A.M., Mazzarol, T., Ghadouani, A., \& Schilizzi, S.G.M. (2014). The resilience architecture framework: Four organizational archetypes. European Management Journal, 32(1), 104-116.

Linnenluecke, M.K. (2017). Resilience in business and management research: A review of influential publications and a research agenda. International Journal of Management Reviews, $19(1), 4-30$.

Liu, X.K., \& Leitch, R.A. (2013). Performance effects of setting targets and pay-performance relations before or after operations. Management Accounting Research, 24(1), 64-79.

Mahama, H., \& Cheng, M.M. (2013). The effect of managers' enabling perceptions on costing system use, psychological empowerment, and task performance. Behavioral Research in Accounting, 25(1), 89-114.

Mallak, L.A. (1998). Measuring resilience in health care provider organizations. Health Manpower Management, 24(4), 148-152. 
Malmi, T., \& Brown, D.A. (2008). Management control systems as a package-Opportunities, challenges and research directions. Management Accounting Research, 19(4), 287-300.

Merchant, K., \& Van der Stede, W.A. (2007). Management control systems (2. ed.). Harlow, Essex, England: Prentice Hall, Pearson Education.

Moulang, C. (2015). Performance measurement system use in generating psychological empowerment and individual creativity, Accounting and Finance, 55(2), 519-544.

Mundy, J. (2010). Creating dynamic tensions through a balanced use of management control systems. Accounting, Organizations and Society, 35(5), 499-523.

Podsakoff, P.M., MacKenzie, S.B., \& Podsakoff, N.P. (2012). Sources of method bias in social science research and recommendations on how to control it. Annual Review of Psychology, 63(1), 539-569.

Ryan, R. M., \& Deci, E. L. (2000). Self-determination theory and the facilitation of intrinsic motivation, social development, and well-being. American Psychologist, 55(1), 68-78.

Schreiber, J.B., Stage, F.K., King, J., Nora, A. \& Barlow, E.A. (2006). Reporting structural equation modeling and confirmatory factor analysis results: A review. The Journal of Educational Research, 99(6), 323-337.

Souza, G.E., Anzilago, M., \& Beuren, I.M. (2017). Efeito da percepção habilitante dos sistemas de custeio pelos gestores no desempenho de suas tarefas. Contabilidade, Gestão e Governança, 20(3), 416-441.

Souza, G.E., \& Beuren, I.M. (2018). Reflexos do sistema de mensuração de desempenho habilitante na performance de tarefas e satisfação no trabalho. Revista Contabilidade \& Finanças, 29(77), 194-212.

Spreitzer, G.M. (1995). Psychological empowerment in the workplace: Dimensions, measurement, and validation. Academy of Management Journal, 38(5), 1442-1465.

Spreitzer, G.M. (1996). Social structural characteristics of psychological empowerment. The Academy of Management Journal, 39(2), 483-504.

Spreitzer, G.M., \& Doneson, D. (2005). Musings on the past and future of employee empowerment. In: Cummings, T. (ed.). The handbook of organizational development. Thousand Oaks: Sage.

Sun, L.Y., Zhang, Z., Qi, J., \& Chen, Z.X. (2012). Empowerment and creativity: A cross-level investigation. The Leadership Quarterly, 23(1), 55-65.

Thomas, K.W., \& Velthouse, B.A. (1990). Cognitive elements of empowerment: An interpretive model of intrinsic task motivation. Academy of Management Review, 15(4), 666-681.

Vallerand, R.J., Pelletier, L.G., Koestner, R. (2008). Reflections on self-determination theory. Canadian Psychology/Psychologie Canadienne, 49(3), 257-262.

Van der Hauwaert, E. \& Bruggeman, W. (2015). The effect of monetary rewards on autonomous motivation in an enabling performance measurement context. Corporate Ownership \& Control, 12(3), 331-356.

Wåhlberg, A.E., \& Poom, L. (2015). An empirical test of nonresponse bias in internet surveys. Basic and Applied Social Psychology, 37(6), 336-347.

Wouters, M., \& Roijmans, D. (2011). Using prototypes to induce experimentation and knowledge integration in the development of enabling accounting information. Contemporary Accounting Research, 28(2), 708-736. 
BBR

17

232

Wouters, M., \& Wilderom, C. (2008). Developing performance-measurement systems as enabling formalization: A longitudinal field study of a logistics department. Accounting, Organizations and Society, 33(4), 488-516.

Zimmerman, M. A. (1995). Psychological empowerment. Issues and illustrations. American Journal of Community Psychology, 23(5), 581-599. 